\title{
Hydatidosis - a zoonosis of unrecognised increasing importance?
}

Hydatidosis, first described in man by Hippocrates (460-379 BC), is caused by infection with the intermediate stage (hydatid cysts) of tapeworms of the genus Echinococcus. Hydatid infection in man leads to morbidity and, in severe cases, death.

There are four species of Echinococcus [1], of which two, E. granulosus and E. multilocularis, cause important zoonotic infections. E. granulosus occurs world-wide while $E$. multilocularis is mainly restricted to holarctic areas, but is also found in parts of Europe, China, Japan and North America. Echinococcus spp. occur in many parts of the world, but the country with most major foci of E. granulosus and E. multilocularis in animals and man is China. One or both species of Echinococcus can be found in $>87 \%$ of China, mainly in the northern, western and central provinces [2].

The global distribution of E. granulosus has been aided, at various times in history, by translocation of domestic animals during periods of human colonisation. Both species of Echinococcus continue to extend their range. For example, in Germany, as a result of the rabies control programme, the fox population has greatly increased and foxes infected with $E$. multilocularis are now being found in parts of the country hitherto considered to be free of the parasite [3]. In Australia, $E$. granulosus has been detected in urban-dwelling domestic dogs used for pig hunting [4] and in wild foxes that have migrated into urban environments [5]. In North America, E. multilocularis has expanded its range through the movement of foxes by members of recreational fox-hunting clubs [6].

The cycle of transmission of Echinococcus spp. to man and domestic livestock involves the interaction between carnivores (definitive hosts) - most commonly domestic dogs, wild dogs and foxes - and herbivores or omnivores (intermediate hosts) - usually sheep, but also other livestock and wildlife species [4]. The wildlife species involved include ungulates, macropod marsupials (kangaroos and wallabies) and several species of rodents. Each host type harbours one of the two morphologically distinct parasite stages: tapeworms in the small intestine of definitive hosts and fluid-filled hydatid cysts, containing the next generation of tapeworms (protoscoleces), in the liver or lungs of intermediate hosts. Intermediate hosts become infected with hydatid cysts through accidental ingestion of tapeworm eggs passed into the environment with the faeces of definitive hosts and definitive hosts become infected with tapeworms through eating protoscoleces contained in the hydatid cysts.

Cysts of Echinococcus spp. grow throughout the life of the host. The cysts of E. granulosus may reach a volume of several litres, but are unilocular. In contrast, the cysts of E. multilocularis consist of masses of small interconnected cysts (multilocular or alveolar hydatid cysts) that spread throughout the affected organ behaving like a slowly growing malignant tumour. The treatment of choice for hydatidosis is surgical removal of the cysts, but multilocular hydatidosis is often inoperable [7].

Several compounds have been assessed as chemotherapeutic agents. The most promising is a benzimidazole derivative, albendazole, with cure rates for unilocular hydatidosis up to $43 \%$ [7]. In patients with multilocular hydatidosis, which is uniformly fatal within 15 years of diagnosis without treatment, benzimidazole treatment increases 15 -year survival rates by up to $80 \%$ [7]. Little financial support has been forthcoming for research into the chemotherapy of human hydatidosis. Without a well-funded strategic approach to research in this area, little progress on improving current methods of chemotherapy can be expected in the foreseeable future.

There have been two important advances for the control of E. granulosus: the development of a vaccine that protects intermediate hosts against infection with the cystic stage of the parasite [8]; and a novel method for detecting infection in the definitive host $[9,10]$.

The vaccine has been developed by recombinant DNA methods. It induces $>96 \%$ protection against experimental challenge with eggs in sheep. In conjunction with conventional control methods - treatment of dogs with praziquantel to remove tapeworms, denying dogs access to offal, and public education - this vaccine will be useful for control or eradication programmes. However, before the vaccine can be used effectively in programmes to control or eradicate E. granulosus, more research is needed to determine the duration of immunity in sheep and other intermediate hosts, protection levels in young animals and effectiveness against naturally acquired infections. The vaccine has the potential for use in man and, by applying the same technology, a vaccine against multilocular hydatidosis could be produced. 
Dogs are central to the domestic transmission of $E$. granulosus. Determining the prevalence of infection in dogs is an important means of monitoring the progress of control programmes and the transmission pressure on intermediate hosts. Infected dogs are detected by administering arecoline hydrobromide to purge their intestinal contents, which are then examined for the hydatid tapeworms [11]. This method has many practical disadvantages and is unreliable in dogs with few worms, which may not be found in the purge sample. A new method for detection of infection in definitive hosts is an ELISA that specifically detects copro-antigens of Echinococcus spp. in the faeces of infected dogs. The test can be used under field conditions and shows great promise as a more practical, reliable and safer means of monitoring the prevalence of dogs infected with $E$. granulosus. It will soon be available as a commercial testing kit (Genzyme Virotech GmbH, 65428 Rüsselsheim, Germany).

Investigations into the epidemiology of Echinococcus spp. in various parts of the world suggest that the current theories regarding patterns of transmission need to be re-assessed. Wildlife reservoirs of infection with $E$. granulosus have been shown to be important sources of infection for sheep [12] and cattle [6]. E. granulosus is the only member of the genus to occur in Australia and the prevalence of infection in rural domestic dogs has fallen steadily in the eastern states during the last 40 years. Nevertheless, cases of human unilocular hydatidosis are still regularly diagnosed in this region [13]. These cases commonly occur in areas with a high prevalence of $E$. granulosus infection in the local wild dog and fox populations. A high prevalence of infection with E. granulosus is found in Australian wild dogs (dingoes, feral dogs, dingo/feral dog hybrids) [14] and in foxes in some rural areas [6]. Foxes frequenting urban environments have also been found to be infected [5]. Faeces deposited by infected foxes and wild dogs in recreation areas may represent a greater public health hazard than is currently recognised.

In an area of Qinghai Province, People's Republic of China, a species of rodent has recently been found to act as an intermediate host for E. granulosus in addition to the traditional domestic livestock species in the same area [15]. This important finding represents the first report of naturally infected rodents, other than hares [16], acting as wildlife intermediate hosts for $E$. granulosus. Although the prevalence of infection in these Chinese rodents is lower than that in domestic livestock from the same area, they may be more important than domestic livestock in the transmission of the parasite to domestic dogs, which commonly catch and eat rodents.

It is not clear whether these variations to the 'normal' transmission pattern for $E$. granulosus represent new developments in the life-cycle, but they emphasise the need for continued international studies on these important parasites, as they have important implications for the design of new hydatid control programmes. Despite being a notifiable disease in Australia, underreporting of human hydatidosis is a perennial problem [6]. This lack of recognition of the public health importance of hydatid disease undoubtedly has an adverse influence on funding for research and control of $E$. granulosus in Australia. One wonders whether this situation prevails in other parts of the world.

D. J. JENKINS

Australian Hydatid Control and Epidemiology Program, 12 Mildura Street,

Fyshwick, ACT 2609, Australia

\section{References}

1. Thompson RCA. Biology and systematics of Echinococcus. In Thompson RCA, Lymbery AJ (eds) Echinococcus and hydatid disease. Wallingford, CAB International. 1995: 1-50.

2. Craig PS, Deshan L, Zhaoxun D. Hydatid disease in China. Parasitology Today 1991; 7: 46-50.

3. Lucius R, Bilger B. Echinococcus multilocularis in Germany: increased awareness or spreading of a parasite? Parasitology Today 1995; 11: 430-434.

4. Thompson RCA, Lymbery AJ, Hobbs RP, Elliot AD. Hydatid disease in urban areas of Western Australia: an unusual cycle involving Western grey kangaroos (Macropus fuliginosus), feral pigs and domestic dogs. Aust Vet $J$ 1988; 65: 188-190.

5. Jenkins DJ, Craig NAT. The role of foxes (Vulpes vulpes) in the epidemiology of Echinococcus granulosus in urban environments. Med J Aust 1989; 157: 754-756.

6. Schantz PM, Chai J, Craig PS et al. Epidemiology and control of hydatid disease. In: Thompson RCA, Lymbery AJ (eds) Echinococcus and hydatid disease. Wallingford, $\mathrm{CAB}$ International. 1995: 233-331

7. Amman R, Eckert J. Clinical diagnosis and treatment of echinococcosis in humans. In: Thompson RCA, Lymbery AJ (eds) Echinococcus and hydatid disease. Wallingford, $\mathrm{CAB}$ International. 1995: 411-463.

8. Lightowlers MW, Lawrence SB, Gaucci CG et al. Vaccination against hydatidosis using a defined recombinant antigen. Parasite Immunol 1996; 18: 457-462.

9. Allan JC, Craig PS, Garcia Noval J et al. Coproantigen detection for immunodiagnosis of echinococcosis and taeniasis in dogs and humans. Parasitology 1992; 104: 347-356.

10. Deplazes P, Gottstein B, Eckert J, Jenkins DJ, Ewald D, Jimenez-Paiacios S. Detection of Echinococcus coproantigens by enzyme-linked immunoabsorbent assay in dogs, dingoes and foxes. Parasitol Res 1992; 78: 303-308.

11. Anon. Parasitological diagnosis of adult tapeworms in carnivores. In: Eckert J, Gemmell MA, Soulsby EJL, Matyas Z (eds) Echinococcosis/hydatidosis surveillance, prevention and control: FAO/UNEP/WHO Guidelines 1982; 70-83.

12. Grainger HJ, Jenkins DJ. Transmission of hydatid disease from wild dogs to sheep in Victoria, Australia. Int J Parasitol 1996; 26: $1263-1270$

13. Jenkins DJ, Power K. Human hydatidosis in New South Wales and the Australian Capital Territory, 1978-1992. Med J Aust 1996; 164: 18-21.

14. Jenkins DJ, Morris B. Unusually heavy infections of Echinococcus granulosus in wild dogs in south-eastern Australia. Aust Vet $J$ 1991; 68: 36-37.

15. He D, Han X, Wu X, Ma Y, Liu H, Zhong T. Epidemiology and aetiological investigations of hydatid disease in Chenduo, Qinghai Province. Chin J Parasitol Parasit Dis 1994; 12 185-188.

16. Schantz PM, Cruz-Reyes A, Colli C, Lord RD. Sylvatic echinococcosis in Argentina. I. On the morphology and biology of strobilar Echinococcus granulosus (Batsch, 1786) from domestic and sylvatic animal hosts. Tropenmed Parasitol 1975; 26: $334-344$ 